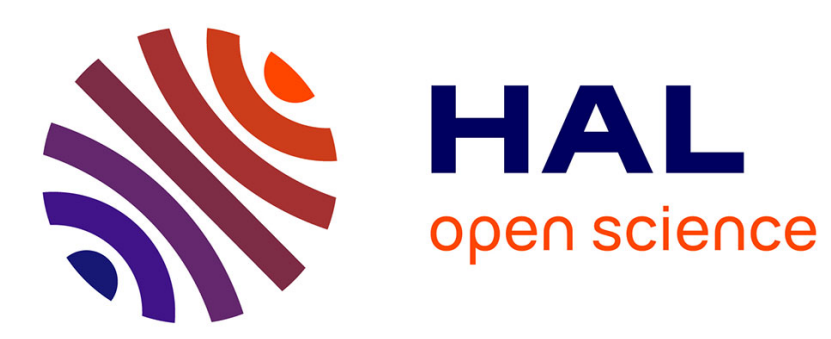

\title{
Open Digital Scholarship in the Humanities: A Review of Needs, Barriers and Opportunities
}

\author{
Paul Arthur, Lydia Hearn
}

\section{To cite this version:}

Paul Arthur, Lydia Hearn. Open Digital Scholarship in the Humanities: A Review of Needs, Barriers and Opportunities. ELPUB 2020 24rd edition of the International Conference on Electronic Publishing, Apr 2020, Doha, Qatar. 10.4000/proceedings.elpub.2020.19 . hal-02544187

\section{HAL Id: hal-02544187 \\ https://hal.science/hal-02544187}

Submitted on 16 Apr 2020

HAL is a multi-disciplinary open access archive for the deposit and dissemination of scientific research documents, whether they are published or not. The documents may come from teaching and research institutions in France or abroad, or from public or private research centers.
L'archive ouverte pluridisciplinaire HAL, est destinée au dépôt et à la diffusion de documents scientifiques de niveau recherche, publiés ou non, émanant des établissements d'enseignement et de recherche français ou étrangers, des laboratoires publics ou privés. 


\title{
Open Digital Scholarship in the Humanities: A Review of Needs, Barriers and Opportunities
}

\author{
Paul Arthur and Lydia Hearn
}

\section{Introduction}

1 The future success or otherwise of the international move toward open digital scholarship is dependent on working with all key stakeholders to overcome logistical, administrative, technological, educational and attitudinal problems to increase the uptake, sustainability and effectiveness of open practices.

2 This requires changes across every part of the system: government agencies, funders, university administrators, libraries, researchers and IT developers.

3 As such, this study sought to shed light on the urgent need for partnership and collaboration between stakeholders at every level to address the barriers to both the policy and practical implementation of open digital scholarship in the field of humanities and social sciences.

4 In this paper, we explore open access performance within Africa, and specifically in four African countries to understand the progress of higher education and research institutions towards openness. This includes contributions from Ghana, Rwanda and South Africa, investigating open research output and dissemination through repositories and open access published sources. Analysis of institutional policies and institutional repositories supporting the production of open, diverse and equitable knowledge provides context in the countries investigated. The study is significant in its use of a variety of sources to understand the open knowledge landscape in four African countries. 


\section{Design and Methodology}

5 This study involved a narrative review to appraise the context and collate evidence on different tiers of information required by policy makers, senior academic administrators, early and mid-career researchers, librarians, platform providers and IT developers, as well as community users. It involved a scoping review of primary research literature obtained using Academic Search Complete, Web of Science, and Google Scholar. A grey literature search of government and non-government organisation policy papers, reports and conference proceedings and the Conversation was undertaken through Google and key network websites. These were supplemented with a secondary search of the references cited in the identified studies.

\section{An overview of the state of the art in the field}

6 The 21st century has been marked by the surpassing for the first time of the volume of digital data over analogue data. As academic practices increasingly become digital, opportunities arise to reshape the future of scholarly communication through more accessible, interactive, open and transparent methods that engage a far broader and more diverse public. Over the past two decades, open access to research outputs, such as the sharing of articles, code, data and educational resources digitally and online, has undergone a profound transition from being merely a theoretical concept to becoming a fundamental global principle for all academic research. Open access has become part of an international move to make all information freely available for use and re-use by every person on the planet, to support equity not only to researchers, but also to teachers, students and the broader public. Today open access is part of a much larger international vision of open digital scholarship, or "an interconnected, equitable, global scholarly ecosystem of well-curated, interoperable, trusted research articles, data and software supported by a diversity of open publishing models" (AOASG, 2019). In other words, open digital scholarship is seen as the creation, production, analysis, or dissemination of new scholarship using digital or computational techniques, or both, that connect academics with the communities they serve.

7 Empowered by social media and networked technologies, the field of humanities and social sciences has moved online - producing more than just articles. Open scholarship is in a transitional moment: research methods and tools are evolving, and scholarly communication is transforming from a closed, print-centric culture to the open sharing of knowledge and data among networks of researchers, organisations, and institutions. This is reflected across academic and societal developments that are changing the way knowledge is produced, shared, distributed, and developed: online publishing, the rise of digital scholarship, personal (and often mobile) computing devices, social media, citizen scholars, and regulations for information access are all a part of this changing picture. The widespread production and adoption of online tools and platforms presents an opportunity for the public and humanities and social science researchers to participate in shared knowledge-based activities as well as in inclusive and representative public spaces. Today society is at a critical juncture underpinned by access to rich metadata, infrastructure, good linkage and above all a desire to make research outputs presented in more FAIR ways to ensure everyone can find, use and reuse them for societal benefit. 
Yet research is illustrating the lack of equitable access to academic research with Wikipedia articles reaching many more public eyes than articles published even in top tier journals. As such, governments and universities are increasingly acknowledging a lack of relevant research relating to how open digital scholarship might be achieved, especially in the field of HASS. In Australia and internationally, institutions are hardpressed to sustain access to publicly funded research as journal, monograph, and digital scholarship costs continue to rise, driven by commercial concerns and influence. Those in the academic sector - including researchers, administrators, and library and information specialists - are voicing concerns about the lack of appropriate open digital research infrastructure at the national and international level, or academic recognition for HASS researchers who adopt or promote these practices.

Efforts we make now to understand and address the barriers-individually and collectively-will fundamentally shape the future for many years to come. As open digital scholarship becomes part of our society, all stakeholders must be intentional about understanding and designing these new open systems to ensure that they are inclusive, equitable, and truly serve the needs of a diverse global community.

\section{Outcomes}

Findings of our study confirmed that despite the growing movement toward open digital communication, researchers continue to be highly influenced by traditional measures of research output which do not encourage digital scholarship through twoway communication and public engagement in research. The study also highlighted current challenges faced by the open digital scholarship movement given the complex nature of HASS including sources such as monographs, book chapters and journals in languages other than English; the use of popular media not considered scholarly papers; the lack of time and energy to develop digital skills among research staff; problems of authority and trust regarding scholarly or non-academic nature of social media platforms; the prestige of large academic publishing houses; and limited awareness of and familiarity with advanced digital applications. This paper/ presentation represents an urgent call for more empirical research around 'missed opportunities' (or missed connections) for universities to promote open digital scholarship in the humanities. Only through clarifying and addressing these barriers can HASS research be presented in usable and understandable ways and data made freely available for uses and re-use by the broader public for societal benefit.

\section{BIBLIOGRAPHY}

"Developing a Strategic Approach to Open Scholarship in Australia: Joint CAUL-AOASG Election Statement." Australasian Open Access Strategy Group, 10 May 2019. aoasg.org.au/developing-astrategic-approach-to-open-scholarship-in-australia-joint-caul-aoasg-election-statement/. 
Beaulieu, Marianne, et al. "Conceptualizing 20 Years of Engaged Scholarship: A Scoping Review." Plos One, vol. 13, no. 2, 2018. doi:10.1371/journal.pone.0193201.

Laporte, Steven. "Preprint for the Humanities - Fiction or a Real Possibility?" Studia Historiae Scientiarum, vol. 16, 2017, pp. 367-378. doi:10.4467/2543702xshs.17.014.7715.

Kingsley, Danny Abigail. "Build It and They Will Come? Support for Open Access in Australia." Scholarly and Research Communication, vol. 4, no. 1, 2012. doi:10.22230/src.2013v4n1a39.

McKiernan, Erin C. “Imagining the ‘Open' University: Sharing Scholarship to Improve Research and Education.” PLOS Biology, vol. 15, no. 10, 2017. doi:10.1371/journal.pbio.1002614.

Montgomery, Lucy, et al. Open Knowledge Institutions, MIT Press OA Books, July 2018. doi: 10.21428/99f89a34.

Narayan, Bhuva, et al. "Scholarly Communication Practices in Humanities and Social Sciences: A Study of Researchers' Attitudes and Awareness of Open Access." Open Information Science, vol. 2, no. 1, Dec. 2018, pp. 168-80. doi:10.1515/opis-2018-0013.

Veletsianos, George. “A Case Study of Scholars' Open and Sharing Practices.” Open Praxis, vol. 7, no. 3, July 2015, pp. 199-209. doi:10.5944/openpraxis.7.3.206.

Ren, Xiang. "The Quandary between Communication and Certification: Individual Academics' Views on Open Access and Open Scholarship." Online Information Review, vol. 39, no. 5, Sept. 2015, pp. 682-97. doi:10.1108/OIR-04-2015-0129.

\section{ABSTRACTS}

The combination of open access and our digital networked environment offers huge potential to make the research outputs of humanities and social sciences more Findable, Accessible, Interoperable and Reusable (FAIR) and more easily available to the broader community for public benefit. Yet despite growing international policy derivatives, open digital scholarship has encountered significant challenges. This study:

- Reviewed key barriers currently hampering the uptake of these policies by diverse university participants (senior university administrators, researchers, librarians, platform providers and developers), policymakers and community users; and

- Examined how these have influenced the fields of humanities and social sciences (HASS).

This paper discusses research undertaken by the Curtin Open Knowledge Initiative (COKI) and participants during and following an Open Knowledge international workshop held in Mauritius in September 2019. The workshop brought together key experts to explore the role of open knowledge in the creation of equitable and inclusive global knowledge landscapes. This paper explores the role of open access and institutional repositories in knowledge sharing and the dissemination of research output from higher education and research institutions within the African continent. The paper reviews the landscape of research output from the African continent; analyses open access research output, overviews of institutional knowledge sharing positions and the dissemination of research output from Ghana, Rwanda, South Africa and Uganda. 
INDEX

Keywords: digital scholarship, open access, open data, knowledge dissemination

\section{AUTHORS}

\section{PAUL ARTHUR}

Chair in Digital Humanities and Social Sciences Director, Edith Cowan Centre for Global Issues School of Arts and Humanities; Edith Cowan University,

Paul.Arthur@ecu.edu.au

(corresponding author)

\section{LYDIA HEARN}

School of Arts and Humanities Edith Cowan University,

L.Hearn@ecu.edu.au 